\title{
Safety-Critical Manuals for Agricultural Tractor Drivers: A Method to Improve Their Usability
}

\author{
Maurizio Cutini ${ }^{1, *}$ (D), Giada Forte ${ }^{2}$, Marco Maietta ${ }^{2}$, Maurizio Mazzenga ${ }^{2}$, \\ Simon Mastrangelo ${ }^{2,3}$ and Carlo Bisaglia ${ }^{1}$ \\ 1 Consiglio per la ricerca in agricoltura e l'analisi dell'economia agraria, Research Centre for Engineering and \\ Agro-Food Processing (CREA-IT), via Milano 43, Treviglio 24047, Italy; carlo.bisaglia@crea.gov.it \\ 2 Ergoproject Srl, Via Antonio Pacinotti 73/B, Roma 00146, Italy; g.forte@ergoproject.it (G.F.); \\ m.maietta@ergoproject.it (M.M.); m.mazzenga@ergoproject.it (M.M.); s.mastrangelo@ergoproject.it (S.M.) \\ 3 PAN-PAN Edizioni Srl, in Via Luciano 15, Milano 20156, Italy \\ * Correspondence: maurizio.cutini@crea.gov.it; Tel.: +39-0363-49603
}

Received: 4 July 2017; Accepted: 31 July 2017; Published: 4 August 2017

\begin{abstract}
This work sets out the planning phases adopted for the first time to put together a manual on injury and accident prevention in the use of farm tractors. The goal is to convey information more effectively than at present, while taking the end users' opinions into consideration. The manual was devised, created, and tested based on a human-centred design (HCD) process, which identified the operators' requirements using a participatory ergonomics (PE) strategy. The main topics of the manual were outlined by engaging the users in a qualitative research activity (i.e., focus groups and workshops with final users), and the contents were prioritized and labelled by way of a noun prioritization activity. The users were involved right up to the choice of graphics and print layout in order to orient the publication to the farming context. The research activity highlighted a divergence between the operators' requirements and the topics currently dealt with in the sector publications. The project resulted in the publication of the "Safe Tractor" manual, which features some innovations. The experience highlighted the need to adopt HCD processes to create innovative editorial products, which can help speed up the dissemination of safety culture in the primary sector.
\end{abstract}

Keywords: focus group; editorial design; health and safety; usability

\section{Introduction}

Agricultural work is one of the most hazardous occupations as it ranks among the top jobs in work injury statistics. The fatality rate of such injuries is six times higher than the rate of all industries combined. In addition, concern about the growing number of leisure-related farm injuries is arising as well.

Figures concerning the burden of these injuries in the EU countries (EU15) show an average mortality rate of 13 deaths per 100,000 farm workers; this is confirmed also in the United States, where an average rate of 22 deaths per 100,000 workers was recorded. In both regions, peaks of more than 30.0 deaths per 100,000 workers were recorded as well [1,2]. Statistics referring to Italy reported tractors as the main cause both of injuries and deadly accidents; as a matter of fact, $56.5 \%$ of the total number of accidents in agriculture and forestry has been related to operating tractor tasks. Within this framework, and considering only the deadly accidents in agriculture and forestry operations, concern arises as $51 \%$ of these happened while workers were operating tractors $(75 \%$ located on field and $25 \%$ while driving on roads). As far as accident dynamics are concerned, machine rollover represents the $77 \%$ of the accidents, while those involving the cardan shaft account for $0.7 \%$, but $66 \%$ of cases result in the death of the operator [3]. 
Children often live, play, or even help on farms, and they are exposed to the dangers of tractors, machinery, and livestock [4]. Among the actions underway to lower the number and seriousness of accidents, effective training methods are increasingly being sought for agricultural machinery operators. Indeed, the "experience" factor alone does not seem to be significant, seeing as, in Italian statistics, fatalities mainly concern "senior" users; $40 \%$ of accidents are with operators aged over 50 [5]. As a result, institutions are intervening with information and worker training initiatives, both owing to new national regulatory obligations [6] and as an awareness-raising and divulgation activity. Furthermore, the design activities should also be more end user-oriented through what is now called a human-centred approach. This means that all designable components of a system have to be fitted to the characteristics of the intended users rather than selecting or adapting humans to fit the system [7]. This work sets out the planning phases adopted for the first time to put together a manual on injury and accident prevention in the use of farm tractors. The Human-Centred Design (HCD) process has also been formalized in the ISO-standard 13407-1999 human-centred design processes for Interactive Systems [8], currently revised by ISO 9241-210, 2010 [9]. These standards state the following key principles:

1. the active involvement of users and clear understanding of user and task requirements;

2. an appropriate allocation of function between user and system;

3. iteration of design solutions;

4. multi-disciplinary design teams.

$\mathrm{HCD}$ is a broad term to describe design processes in which end users influence how a design takes shape. It is both a broad philosophy and variety of methods [10]. It came to the fore through Norman and Draper [11], who focused on users' needs, carrying out an activity/task analysis, performing early testing and evaluation, and designing iteratively. According to Norman [12], the role of the designer is to facilitate the task for the user and to make sure that they are able to make use of the product as intended, with a minimum effort to learn how to use it. Norman notes that often the manuals that accompany products are not user-centred; consequently some design principles are needed to guide the design.

HCD requires the full exploration of the user's needs and the intended uses of the product. The need to involve actual users, often in the environment in which they would use the product being designed, is a natural evolution in the field of user-centred design [13]. Their involvement leads to more effective, efficient, and safer products and contributes to the acceptance and success of products [14]. The main methods used in user-centred design are as follows [15]:

- field studies (including contextual inquiry);

- user requirements analysis;

- iterative design;

- usability evaluation;

- task analysis;

- focus groups;

- formal heuristic evaluation;

- user interviews;

- prototype without user testing;

- surveys;

- informal expert review;

- card sorting;

- participatory design.

Before any usability design can begin, it is necessary to understand the context of use for the product, i.e., the goals of the user community, the main user, the task, and the environmental 
characteristics of the situation in which it will be operated [16]. The work set out here focuses on designing a manual on the health, safety, use and maintenance of farm tractors. When drawing up these publications, generally the contents they need to include are taken into account but not how they are read and used by the end reader. This research used a method that is "user-oriented" in all its phases of realization [17]. Every phase of the manual's definition envisaged the farm workers' active and direct participation, in particular concerning the choice of contents and their depiction in graphic form.

\section{Materials and Methods}

The first phase of the project set out to analyse the context in question. As a result, existing manuals were acquired to identify which topics needed to be dealt with and to assess their current presentation, organization, and reception. What emerged from the current publications was used as the basis for the workshops with the farm workers (WS1). They were all Italian and from the Bergamo area of the Lombardy region. During the workshops, the farm workers discussed and outlined their knowledge requirements, which were then put forward and tested in subsequent focus groups $[18,19]$ involving a larger number of users. Once the context as well as the workers' real knowledge requirements had been defined, the next step was to devise the layout of the new publication. The iterative design phase began with a noun prioritization approach. Noun prioritization is the process of assigning priorities to things or tasks [20]. Prototypes were tested through expert observation and user workshops (WS2), until the final publication design was reached.

\subsection{Issued Manual Evaluation: Definition of the Context in Question}

The activity began by analysing a sample of equivalent publications to the planned one [21]. An analysis was made of nineteen publications by public institutions, the main focus of which was the safety of farm equipment (see list in Appendix A).

The aims were to catalogue the editorial features and to single out the best/worst practices in terms of clarity, immediacy in getting the message across, impossibility of misinterpretation, and completeness. Possible interesting topics and gaps in the communication process were identified in order to reach a first hypothesis on how to develop the new publication and to test it by involving final users, who were able to recognize the most and least mentioned topics and therefore to identify the ones not mentioned.

\subsection{Preliminary Screening: Individual Interviews with Experienced Users}

The first activities were individual interviews with three expert workers (41 to 52 years old, 20 to 40 years of experience). They were asked questions on their habitual use of safety manuals and user and maintenance manuals, their knowledge requirements, the information that they think a sector worker should know, and what they expect from a new publication on health and safety in the sector.

By comparing the results of this activity with what emerged from the previous benchmarking on other publications, it was possible to define a first structure (i.e., selection of topics, style of the illustrations) of the new publication.

\subsection{Workshop 1: Further Investigations to Outline which Topics to Include in the New Publication and on Health and Safety Manual User Experiences}

A workshop was organized with a larger group of operators (five experienced and three less experienced users, average age of 41, standard deviation of 6.37). The goal of the workshop was to obtain confirmation of what had emerged in the interviews. The experienced operators had 28.5 years of experience, while the less experienced operators counted 14.6 years. As a result, a further investigation could be made of their health and safety manual user experiences in order to more precisely define the topics to include in the new publication. 
The results were compared with the initial hypothesis made after analysing the manuals, leading to the outline of a first layout (i.e., division into chapters, selection of topics) for the new publication.

\subsection{Focus Group: Definition of the New Publication}

Contrary to group interviews, which collect data from several people at the same time, focus groups explicitly use group interaction as the core of the method. This means that instead of the researcher asking to each person a question in turn, participants are encouraged to discuss and exchange comments and questions on experiences and points of view [19]. Focus groups are helpful "when insights, perceptions and explanations are more important than actual numbers" [22].

The aims of the focus group were:

- to further investigate how the users interact with the manuals;

- to devise the layout of the new publication.

It was possible to recruit twenty-two experienced farmers:

- landowners, agricultural contractors, farm labourers, and seasonal workers;

- $\quad$ aged between 20 and 60 (average age $36, \mathrm{SD}=12.46$ );

- all men.

The users were divided into three focus groups, each lasting one and a half hours (one with eight participants, two with two). A set of over 15 users is usually considered sufficient to perform a categorization activity such as noun prioritization [23].

They were attended by a moderator, who conducted the activities while promoting the participation of all and asking some open questions, and an observer who took notes and made additional questions in the final phase of the discussion. As agreed with the users, all of the sessions were video recorded.

Once the context as well as the workers' real knowledge requirements had been defined, the layout of the new publication was devised and then checked using noun prioritization. This last is an effective method for representing users' implicit mental models, which reveals their expectations on how the contents should be categorized. Once the mental models and implicit categorization are known, the information can be organized so that it is easier to find and use. This technique consists of showing the users cards with the name or description of a particular content. The users are then asked to divide the cards into groups and to put the topics into set categories. The participants were invited to categorize the topics and put them in order from the most to the least important. The categories of topics presented in the "Safe Tractor" publication were selected by researchers following the results from issued manual evaluation and input collected from users involved in the pre-focus group participatory activities (i.e., workshops and interviews). There were three set categories: (i) information, (ii) training, and (iii) action.

Sixteen topics (Table 1) had to be put into categories (six in each of the information and training categories and four in the action category), which had been selected from the results of the analysis of the topics dealt with in the existing publications and in WS1 (topics considered more/less interesting by the participants). 
Table 1. The categories and the relevant topics proposed to the participants of the focus group.

\begin{tabular}{|c|c|c|}
\hline Category & Topic & Description \\
\hline \multirow[t]{6}{*}{ Information } & driving in the field & $\begin{array}{c}\text { risks of injuries and accidents that can take place } \\
\text { while driving in the field }\end{array}$ \\
\hline & on-road driving & $\begin{array}{c}\text { risks of injuries and accidents that can take place } \\
\text { while driving on roads }\end{array}$ \\
\hline & regulations & $\begin{array}{l}\text { presentation of the health and safety regulations } \\
\text { concerning agricultural sector workers }\end{array}$ \\
\hline & environmental risks & $\begin{array}{l}\text { the impact of work operations on the biological } \\
\text { and/or atmospheric conditions }\end{array}$ \\
\hline & $\begin{array}{l}\text { risks linked to use of the } \\
\text { farm vehicle }\end{array}$ & $\begin{array}{l}\text { dangers connected to use during farming and } \\
\text { maintenance operations }\end{array}$ \\
\hline & statistics & $\begin{array}{c}\text { e.g., number of workers in the sector, number of } \\
\text { accidents/injuries }\end{array}$ \\
\hline \multirow[t]{5}{*}{ Training } & work environment & $\begin{array}{l}\text { basic notions on environmental and } \\
\text { organizational aspects affecting work activities }\end{array}$ \\
\hline & checklist & $\begin{array}{l}\text { a 'paper and pencil' list that workers can use to } \\
\text { check that the work is done in safety }\end{array}$ \\
\hline & maintenance & $\begin{array}{l}\text { information on the ordinary maintenance } \\
\text { activities to perform on the machine every day }\end{array}$ \\
\hline & work postures & $\begin{array}{l}\text { indications on the postures to assume to prevent } \\
\text { muscle/bone problems linked to the farm work }\end{array}$ \\
\hline & first approach to the vehicle & $\begin{array}{c}\text { indications on how to work safely designed for } \\
\text { users new to the sector }\end{array}$ \\
\hline \multirow[t]{3}{*}{ Action } & $\begin{array}{l}\text { safety signs } \\
\text { driving in the field } \\
\text { on-road driving }\end{array}$ & \\
\hline & $\begin{array}{l}\text { injuries from use of the } \\
\text { vehicle }\end{array}$ & $\begin{array}{l}\text { information on the most likely injuries linked to } \\
\text { the use of farm vehicles }\end{array}$ \\
\hline & first aid & basic first aid procedures \\
\hline
\end{tabular}

\subsection{Workshop 2: Discussion of the Draft with Experienced Users}

The iterative design phase began after the focus group and noun prioritization activities. The authors of the manual were involved in drawing up the contents of the new publication, with the request to follow the indications below in order to create a text built around real users' requirements: "Always remember who your readers are: not just your boss or whoever has to review your texts, but the end users" [24]. The prototype was tested with the users in workshops (WS2) using the "walk-through/talk-through" method $[25,26]$. The users had the tasks of reading the contents, marking any passages that were difficult to understand and/or not very clear, and deciding the best solution for the graphical layout and for the order in which the topics were presented. During WS2, the publication was read out loud, followed by a free discussion. During this second session, the discussion was oriented in order to verify and further investigate subjective dimensions [27], such as:

- attractiveness: assessing whether the handbook is interesting enough to attract and keep the users' interest, with particular attention to the aspects/elements that they prefer and/or have most caught their interest;

- comprehension: assessing whether the transmitted message is clear and how this is understood by users;

- $\quad$ acceptance: ensuring that the handbook does not contain offensive or unpleasant elements and that it actually reflects users' convictions and beliefs;

- personal involvement: checking if users perceive that the instrument was designed precisely for their needs;

- persuasion: assessing whether the handbook convinces users to implement the proposed behaviour. 


\section{Results}

\subsection{Issued Manual Evaluation}

A vast theoretical overview of the topic of "farm vehicle and equipment safety" but little information/practical training (e.g., how to get into and out of a tractor safely even though this is one of the most widespread causes of injuries) occured in $57.9 \%$ of the analysed publications. Table 2 shows the frequency with which the topics came up.

Table 2. Topics seen in the publications and their frequency.

\begin{tabular}{cc}
\hline Topic & Frequency (\%) \\
\hline Work environments (theory) & 89.5 \\
Safety signs & 78.9 \\
Farm vehicle safety (theory) & 73.7 \\
Statistics on the frequency of accidents & 57.9 \\
Checklist & 31.6 \\
Driving the farm vehicle on the road & 26.3 \\
Maintenance operations & 15.8 \\
First approach to the farm vehicle & 15.8 \\
First aid & 10.5 \\
\hline
\end{tabular}

Almost $85 \%$ of the analysed publications were divided into a range of six to eight chapters, further divided into paragraphs and subparagraphs. They were set out in the style of a compilation, with quotations from the regulations in force and technical descriptions of the risks to an operator when using a tractor. The images accompanying the texts were technical drawings taken from the regulations or drawn following the same type of model. $10 \%$ of the publications examined give a practical and concise presentation of the main dangers connected to the use of tractors as well as the solutions to be adopted in an emergency; the texts are accompanied by examples in the form of non-technical images. Lastly, the remaining 5\% contain notes on the regulations and give information on day-to-day work activities; each topic is presented according to information/training sheets with example illustrations accompanying the text, subsections, and summary tables. Through this analysis, it was possible to identify the institutions' training/information priorities, which were then compared with the user requirements previously collected.

\subsection{Preliminary Screening}

The users interviewed individually $(n=3)$ underlined the need for publications on safety that give practical and concrete indications on "what to do", "what not to do", and "what to know" to avoid or prevent accidents. They highlighted that farm sector workers have a great need for training since they consider the existing publications unsuitable and incomplete.

The operators interviewed expressed information/training needs in contrast with what was found in the analysis of the existent publications. From the interviews, it also emerged that user and maintenance manuals are given little use both because there is not always a space designed for them and because the texts are particularly long and not very clear when those consulting them would instead like to find quick solutions to problems on the spot. Even when a tractor is used for the first time, the tendency is to ask more experienced colleagues.

\subsection{Workshop 1}

The workshop with a larger group of operators (five experienced and three less experienced, average age of $41, \mathrm{SD}$ of 6.37 ) resulted in the classification of the topics that the users thought most useful (obtained from the average of the topics considered most useful by the five experienced users 
and the average of those considered most useful by the three less experienced users). These are presented separately depending on the amount of experience of the operators (Table 3).

Table 3. Topics in order of usefulness for the interviewed users, separated according to experience.

\begin{tabular}{ccc}
\hline Classification & Experienced Users & Less Experienced Users \\
\hline 1 & Checklist & First approach to the farm vehicle \\
2 & On-road driving & Work environments (practical information) \\
3 & Maintenance operations & Checklist \\
4 & First aid & On-road driving \\
5 & Farm vehicle safety (practical information) & Maintenance operations \\
6 & - & First aid \\
\hline
\end{tabular}

The comparison (Figure 1) between the topics quoted by the operators as useful and those treated as such in the publications highlights the divergence $(r=-0.69)$ between what the users would like to read and what they find in the manuals.

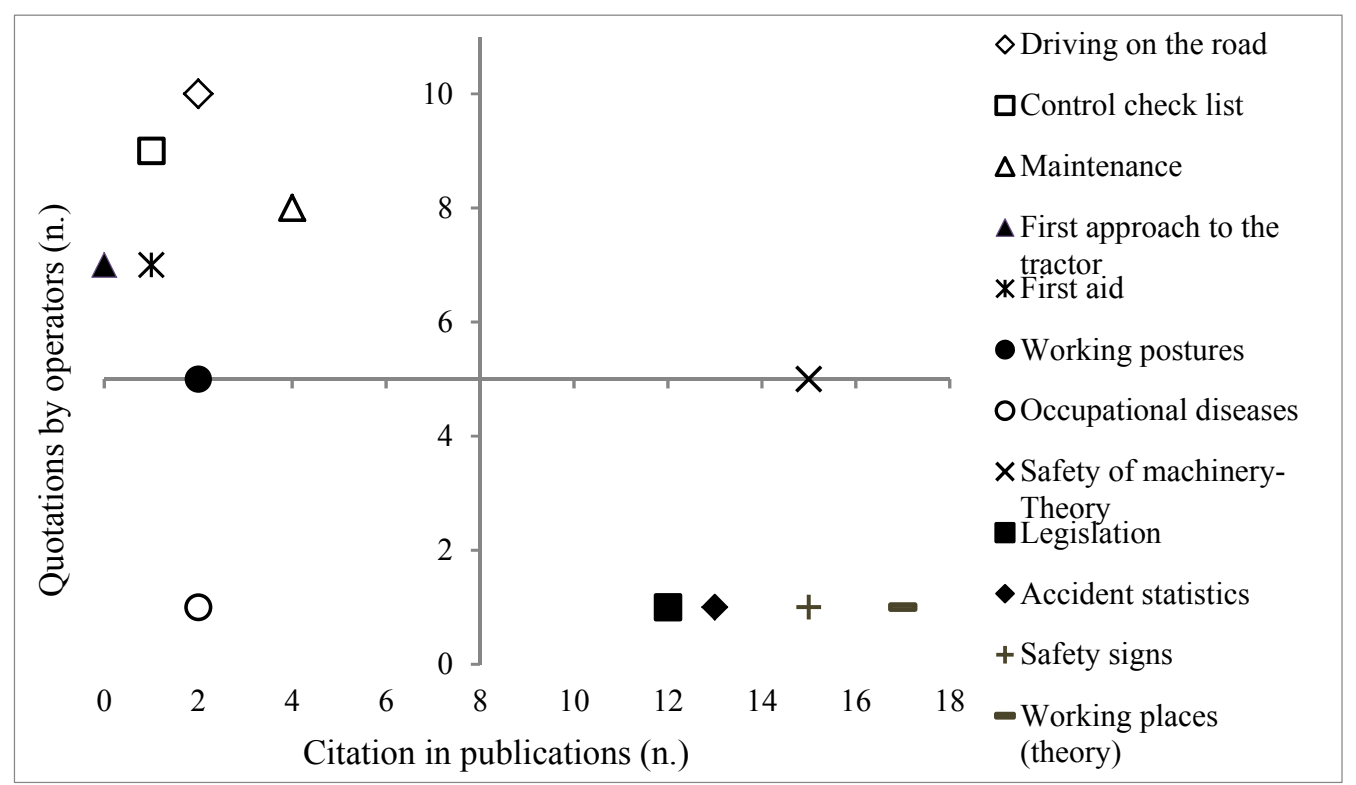

Figure 1. The $x$-axis shows the topics dealt with in the publications, the $y$-axis shows the topics quoted by the operators.

\subsection{Focus Groups}

\subsubsection{User and Maintenance Manuals}

The users only questioned user manuals to find out what error codes mean or the maximum admissible load weight. The vehicle owners only consult the manual when they are dealing with a new model, while they state that during the tractor's life span they ask either the dealer where they bought it or colleagues with the same model. The users complained about the fact that the information in the publications is not very comprehensible because they are written in a complex or superficial manner. Another problem is that these texts are not very accurate translations into Italian of instructions written in other languages. Examples of users' answers were: It only gets opened when it's absolutely necessary; It's written for clever clogs; The information's there, but we can't put it into practice; At times the only solution they give is to go and consult an authorized dealer. The participants pinpointed the length of the texts as the main factor discouraging them from reading and claimed that, in previous years, the dealers had suggested to the manufacturers that they divide the manuals into several leaflets precisely to make them easier to read. 


\subsubsection{Safety Manuals}

All the operators admitted that they only read safety publications when they had to; for example, during a course held on the farm. They said they had leafed through them while waiting in the offices of some institution or other or because they came with the sector journals. They deemed them all to be very similar to one another, outdated and not really responding to their actual work conditions. Examples of operators' comments resulted: I'm not going to read them until I get sent on a course; When you go to the Italian farmers' union to sit in a queue, you leaf through them because that's all there is in the waiting room; It didn't say anything new. It was a waste of time. They did not express the need for clearer publications because they appeared skeptical and almost annoyed by the aims of these publications; they talked about them as containing lists of "obligations", which involved costs of varying proportions in order to meet them. "They're a cost, not a gain." The data categorized and summed up shows that the participants are sensitive to health/safety problems, but in practice they have difficulty in applying suitable measures in their everyday working conditions.

Nevertheless, it emerged that they wanted to be informed on these topics so long as those doing the information and training activities (public institutions, manufacturers, lawmakers) accounted for their real working and personal needs (e.g., clearer instructions, basic and useful information).

\subsubsection{Noun Prioritization}

The same people took part in the noun prioritization as took part in the focus groups. Of the 22 people present in the focus group, 19 took part in this second trial (average age 38, SD was 12.39). The preferences marked by the users were shown as the total of the degree of preference attributed to the topic (from 1, agree with most, to 5, agree with least) divided by the number of participants. For every category, the average of the user preferences given to each topic was compared with the average presence of the same topics in the 19 texts analysed during the issued manual evaluation activity. The results (Figures 2-4) show an inverse polarization on almost all the topics proposed; the topics deemed most interesting by the participants are those dealt with least in the publications analysed.

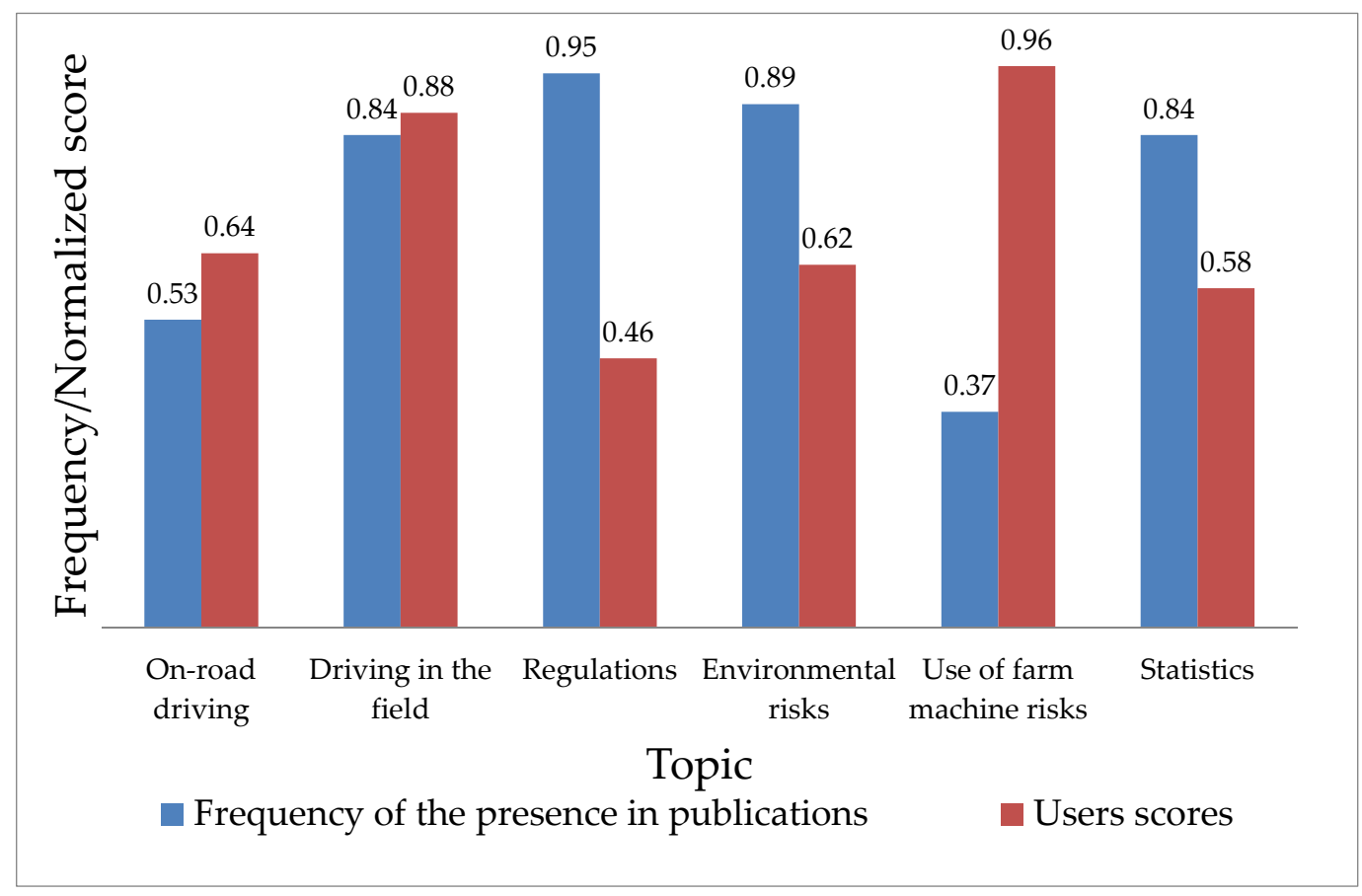

Figure 2. Cont. 


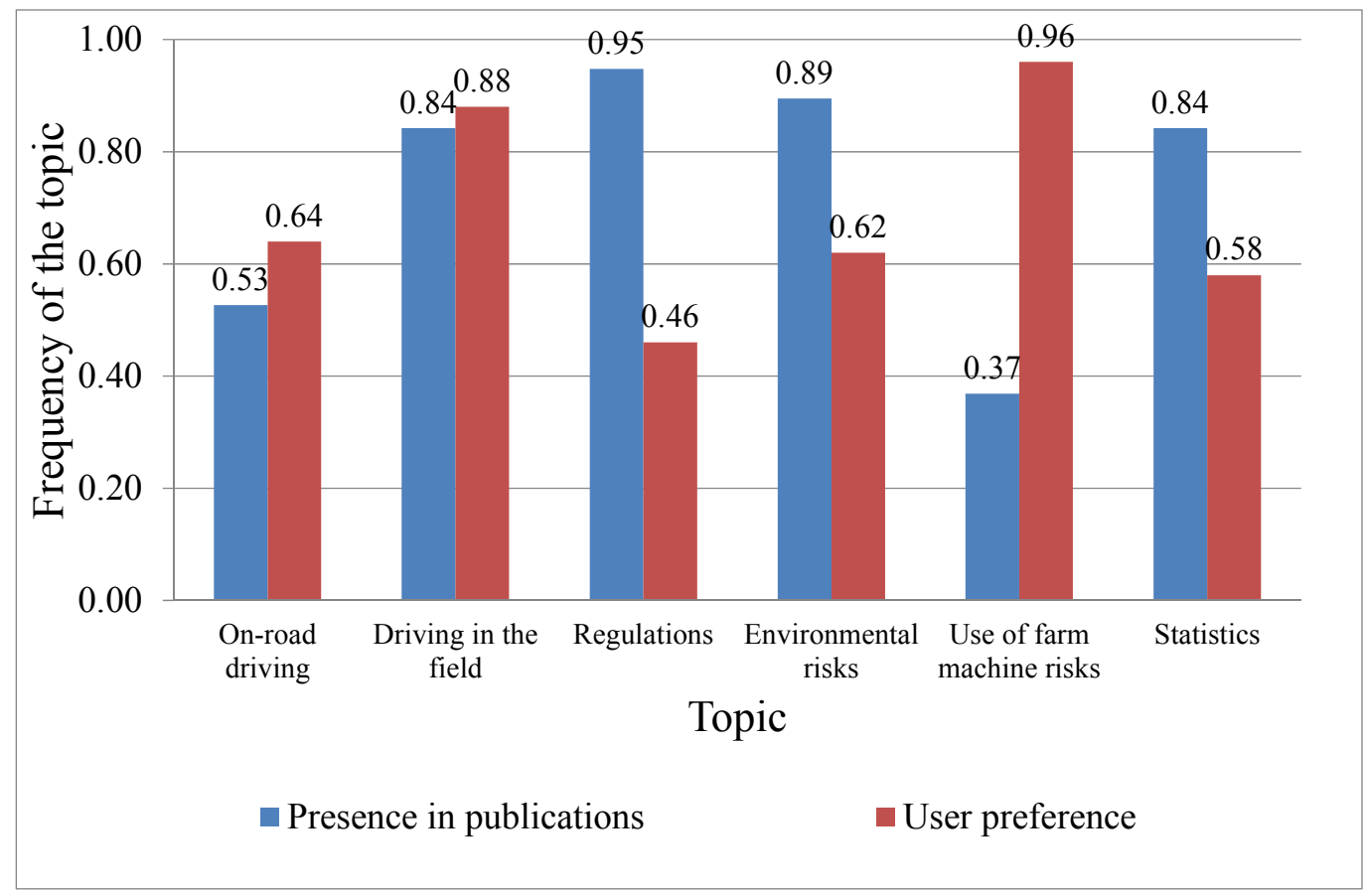

Figure 2. Frequencies of the topics dealt with in the sample of the 19 analysed publications (blue) and the normalized average scores expressed by the 19 operators (red) in the Information category.

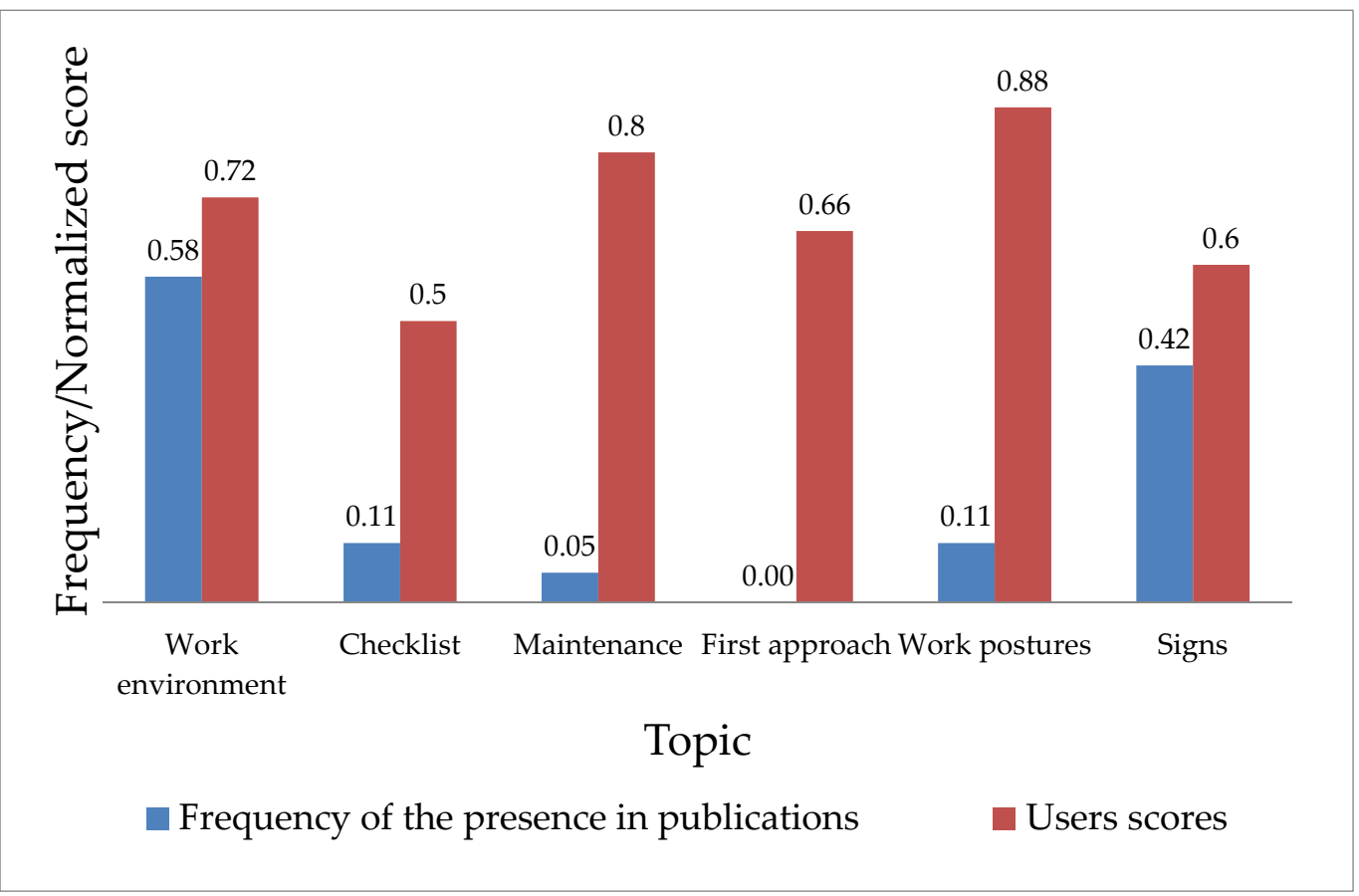

Figure 3. Cont. 


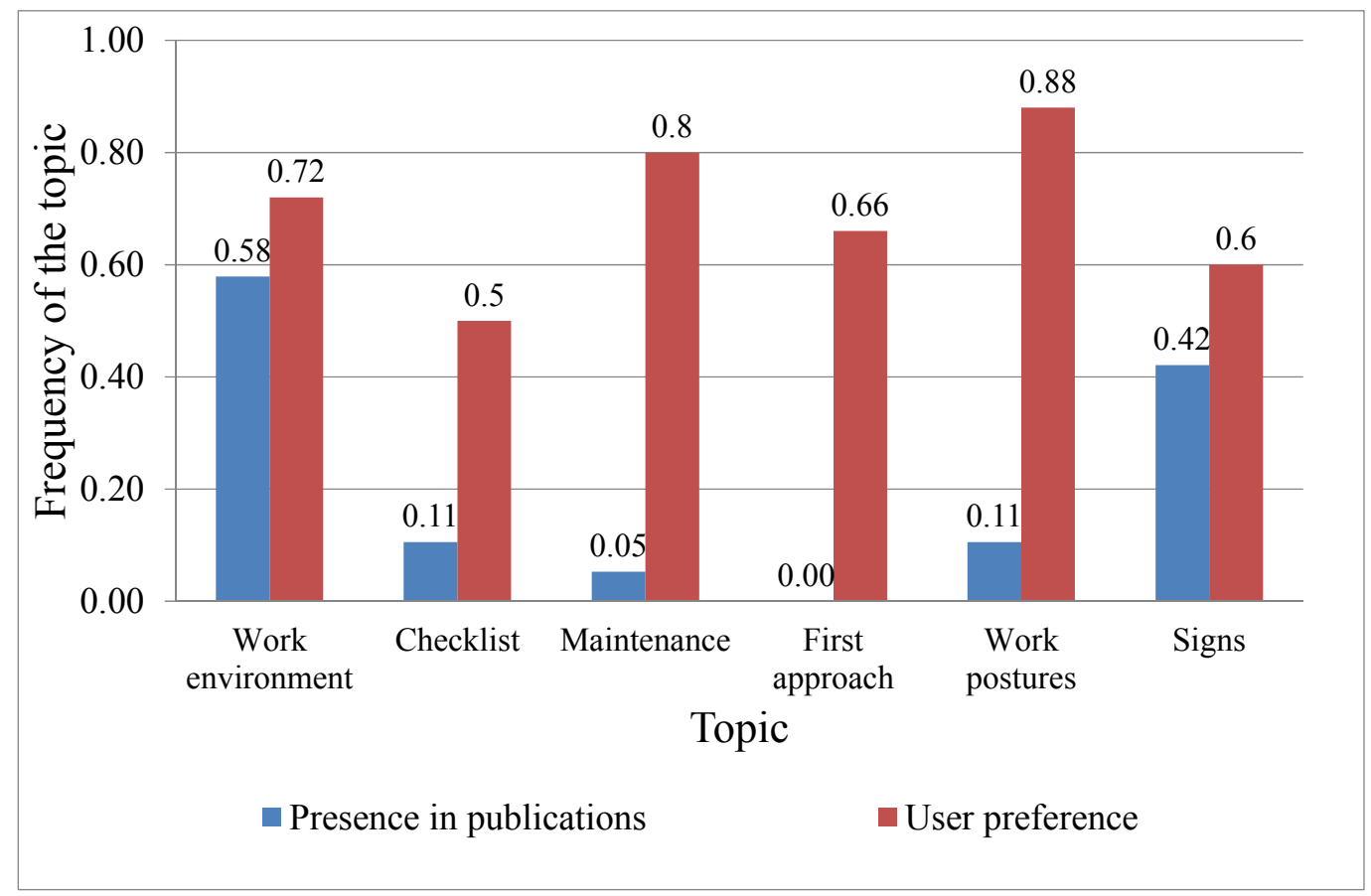

Figure 3. Frequencies of the topics dealt with in the sample of the 19 analysed publications (blue) and the normalized average scores expressed by the 19 operators (red) in the Training category.

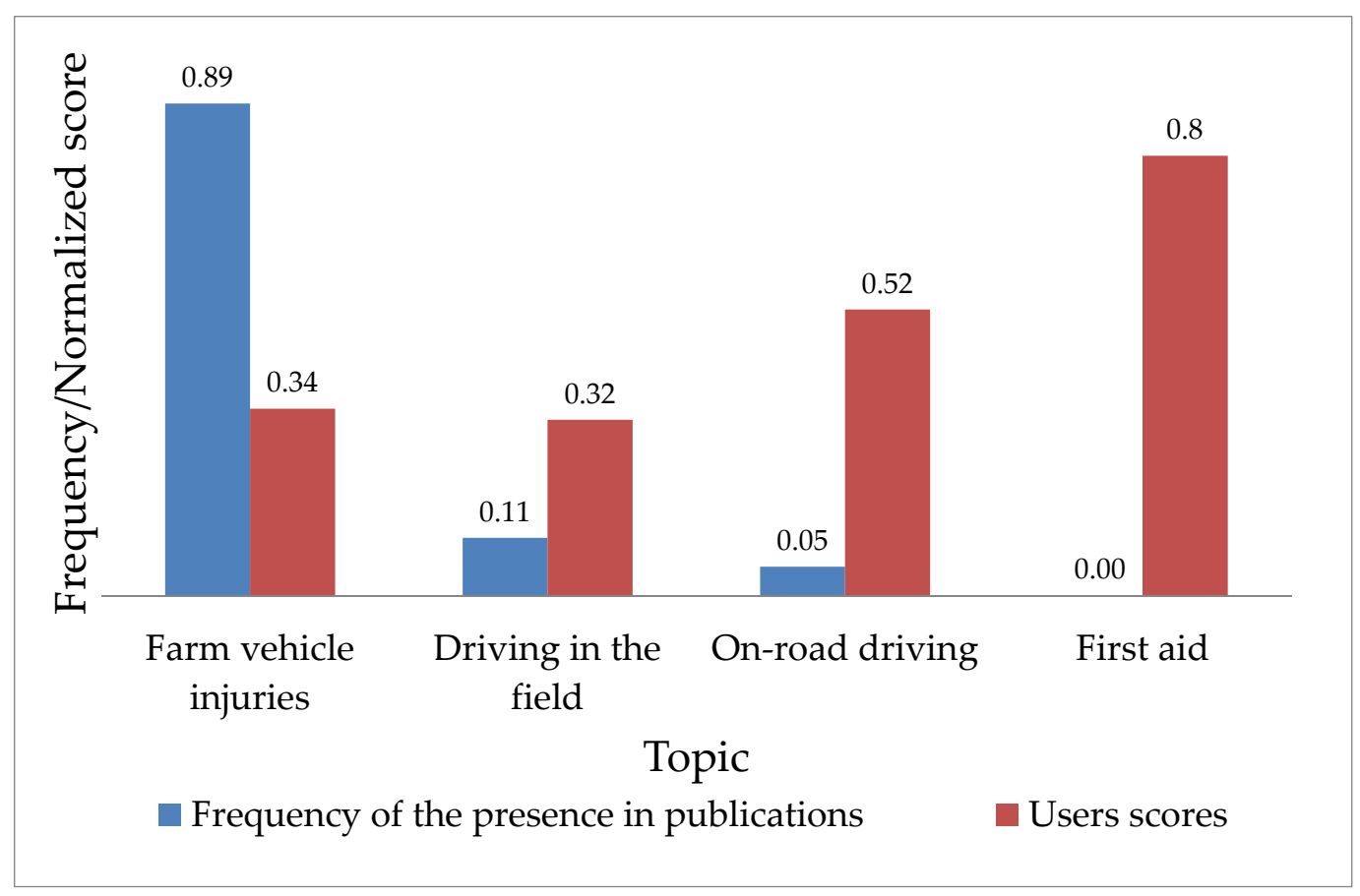

Figure 4. Cont. 


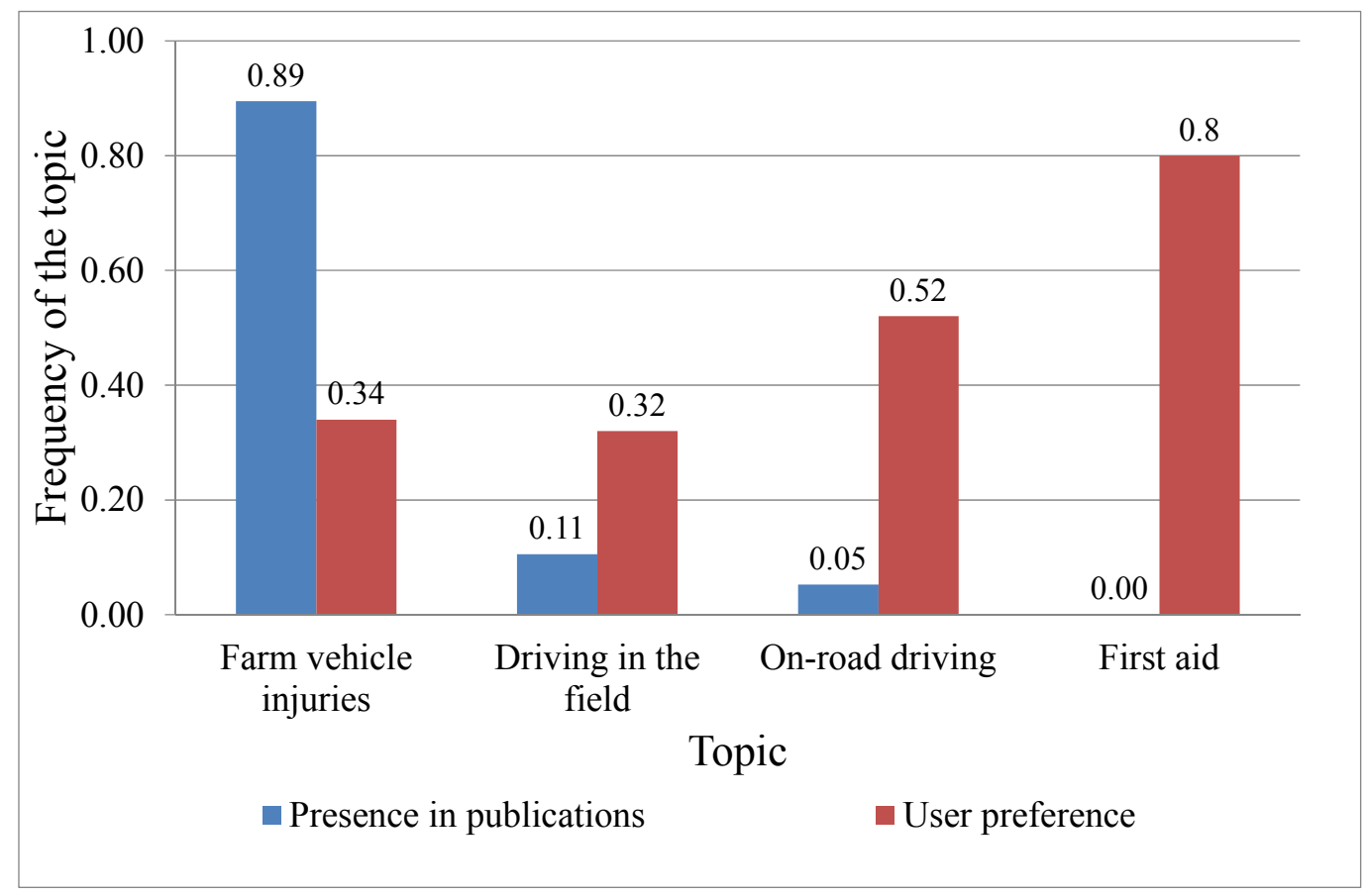

Figure 4. Frequencies of the topics dealt with in the sample of the 19 analysed publications (blue) and the normalized average scores expressed by the 19 operators (red) in the Action category.

At the end of the noun prioritization activity, the participants were asked to comment in groups on the topics they considered most significant or they found more difficult to place.

Regulations, belonging to the Information category were ranked among the bottom positions by the absolute majority of the participants. The users maintain that, in the publications, there is usually just a list of regulations; therefore they are considered of little interest. A topic that caused perplexity was the Checklist in the Training category; the users attributed little importance to the topic, not out of a lack of interest but because they thought that a tool of this kind (a list on paper to tick off with a pen) could be considered not very usable for the workers. Statistics, in the Information category, was the main topic of final discussion since half of the participants ranked it among the top positions, while the other half put it among the bottom. The users expressed their opinions by basing themselves on their previous experiences with sector manuals. The workers with most experience justified their choice by maintaining that using statistics on injuries and accidents that really happened could be a good way of raising awareness and convincing people of the need for safety when reading a publication; the users with less experience instead claimed that statistics are just seen as lists of numbers and ignored. The conclusion drawn was that users would declare greater interest in some topics if, in their experience, they had found them dealt with in a more explicit, concise, and, above all, less abstract manner (e.g., as far as statistics are concerned, they would prefer to find a smaller number of figures in the publications but ones linked to the most frequent accidents and injuries, rather than a mass of generic data). Another interesting piece of data that emerged from the discussion is that, when prompted to express personal expectations about the publications, the users admitted that they did not feel the need for a new publication, but that they would feel motivated to read it if the message was mainly put across through images and a few texts. In addition, they agreed in considering the division into areas (Information, Training, Action) as complete. They also asked for the topics to be dealt with in the new publication while taking their real working conditions into consideration. Furthermore, they explicitly requested that the excessive technicalities found in the previous publications be avoided. 


\subsection{Workshop 2: Iterative Design}

After gathering the information, work began to make the manual prototype defining some elements such as the position of the illustrations on the page, the layout of the text in boxes, the thumb index at the side, and the print medium.

The first prototype of the manual (Figure 5) was presented to a group of experienced users, who were asked to assess the clarity of the contents and the coherence of the chosen graphics. From the preliminary investigation, it emerged that the areas the publication had been divided into (i.e., Information, Training, and Action) reflected the classification and institutional lexicon that had been identified as a worst practice during the manual evaluation.

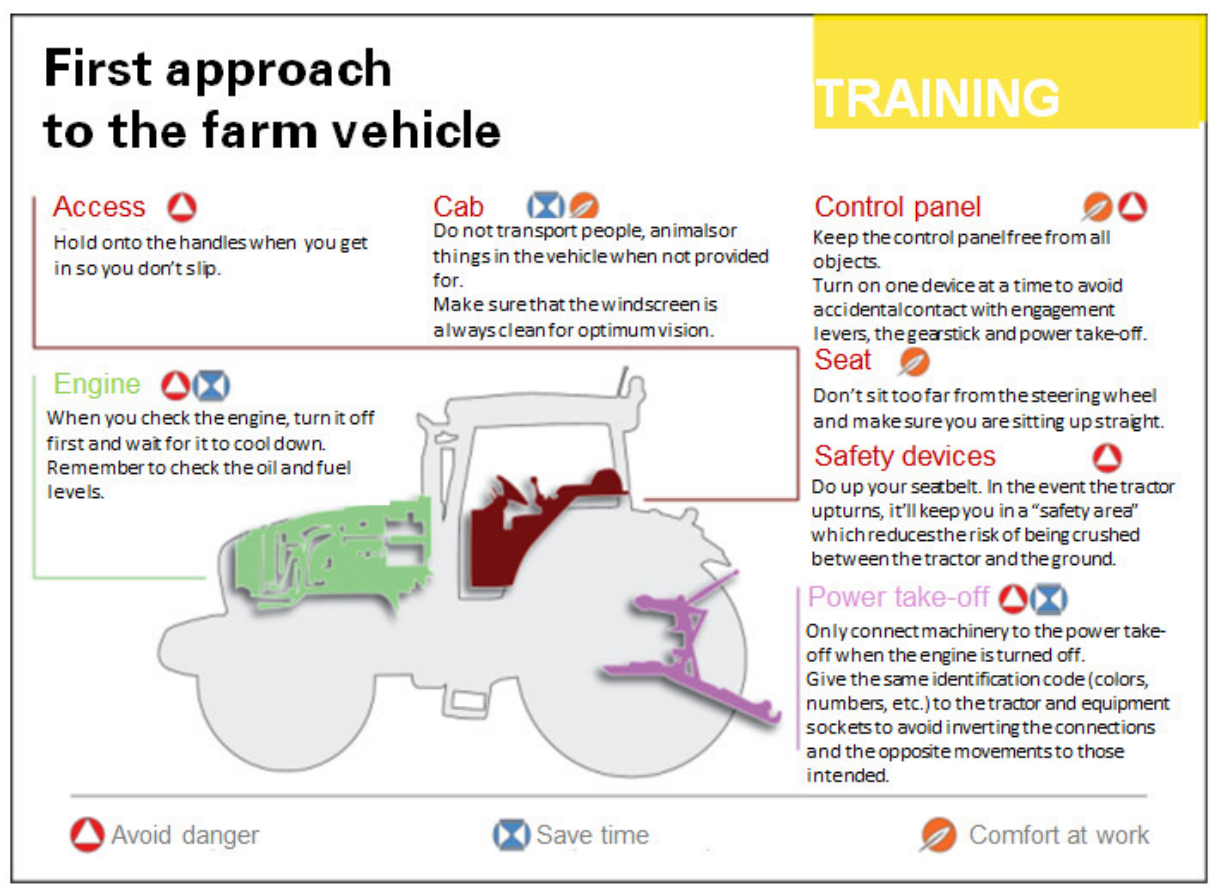

Figure 5. Prototype of manual page setting: example on the driver's position.

Hence, in order to ensure that the contents are conveyed effectively, the general organization of the text was reviewed to make it task-oriented. As a consequence, it was decided to separate the formal "regulations" from the "real" ways of using a vehicle according to the workflow defined with the users.

Therefore, the publication was divided into the chapters:

1. Vehicle at rest (what you need to know before you start to drive):

- Before you start work;

- Safety devices;

- Attaching equipment;

- Maintenance activities;

- Work shifts and stress.

2. Work in the field:

- Danger of overturning;

- Use of equipment;

- Presence of people around the machine. 
3. On-road transport:

- $\quad$ Conduct on the road;

- How to behave with car drivers;

- Load quantities;

- Safety signs.

4. Annexes:

- What to do in the event of accidents;

- Maintenance checklist.

The group of experienced users then reviewed the texts according to the new layout for completeness, deeming it a good idea to also include a chapter on vocational illnesses, which had not been included in previous versions.

This additional chapter contains indications on:

- danger from chemical agents;

- danger from physical agents;

- biological risk.

Following the indications, the authors decided on further graphical elements, in particular the use of boxes and a review of the style of the illustrations (Figure 6).

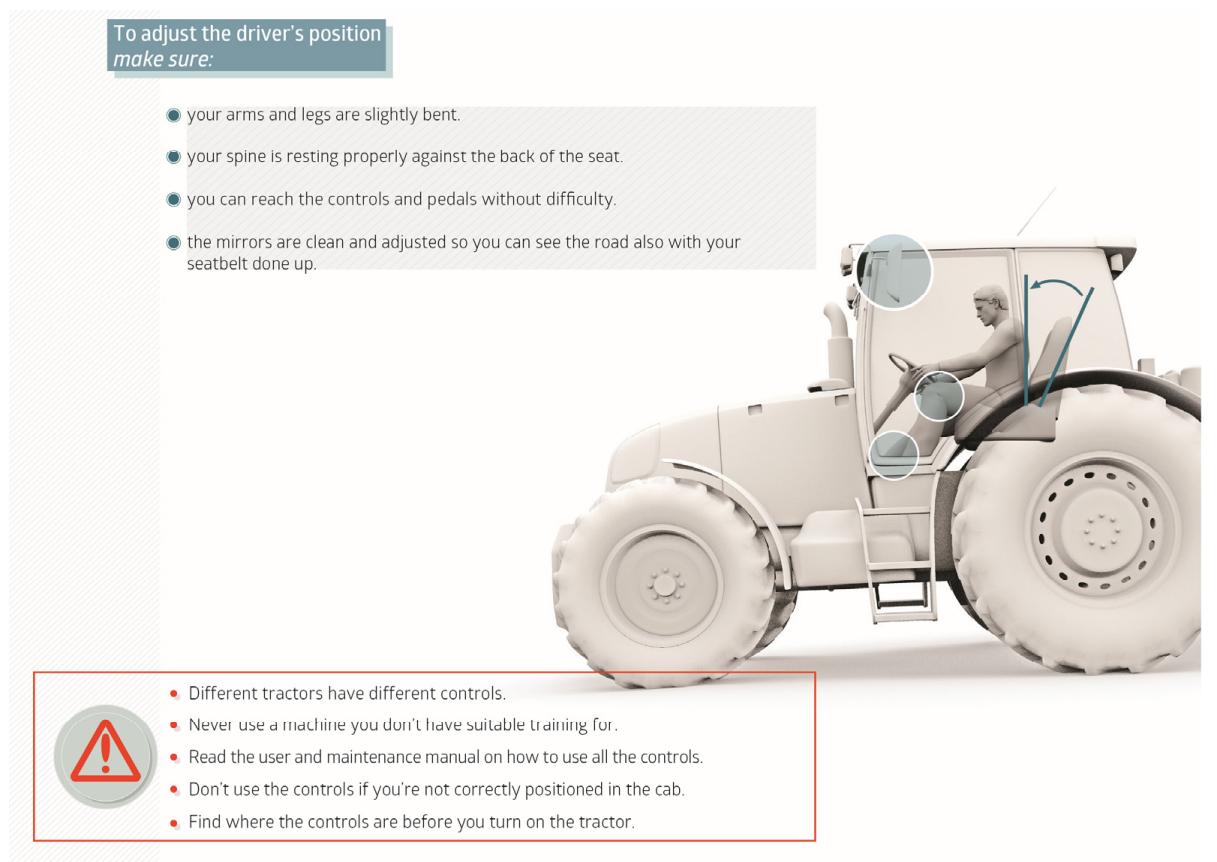

Figure 6. Intermediate draft of the section on the driving position.

To arrive at the final version of the publication, another four prototypes were made, which were assessed iteratively with direct user involvement. Participants were asked to read the prototype of the publication aloud. This allowed researchers to understand how workers wanted to use the manual for making meanings that are relevant to them, encouraging discussion, making connections with their lives, informing their view of themselves and others, asking themselves questions, and using the text to create personal storytelling [28]. 
Moreover, when read out loud, the participants found further issues, which they had not identified previously or pointed out in the feedback provided after reading the manual to themselves such as the presence of decorative elements and illustrations in partial contrast to the procedures described in the texts (e.g., the illustration of some personal protective equipment not set out in the text), complicated sentences (e.g., the presence of two negatives or long sentences with lots of clauses), and not very clear descriptions of activities (e.g., for attaching a winch and/or the procedure for making a U-turn on a slope). After this workshop, the authors came up with the final draft (Figure 7).

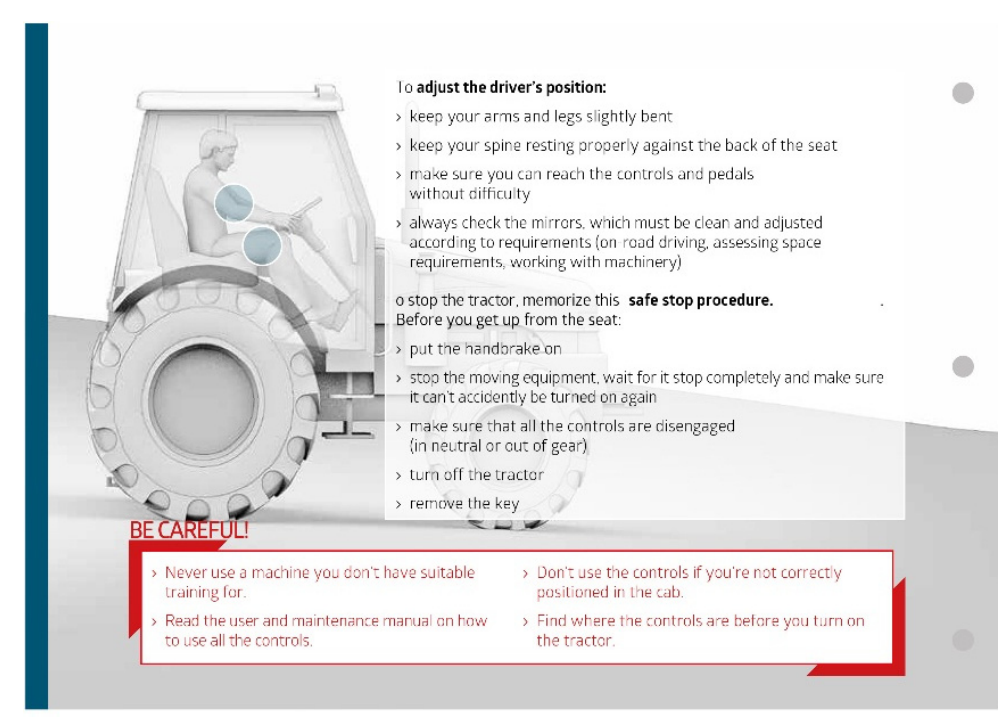

Figure 7. Final draft on the driving position.

\subsection{The Final Manual}

The final manual was drawn up by CREA-IT (Italian Agricultural Research Council) and ENAMA (Italian Institute for Agricultural Mechanization) experts, assessed and reviewed by experienced users, and, where necessary, simplified and updated to fit the needs expressed by the users. As far as the chosen graphics are concerned, the four colours of the different sections are included on the cover (Figure 8) to make the four areas that the manual is divided into easy to identify. Furthermore, the areas can be recognized inside the publication thanks to a vertical thumb index in the same colour as the area and page number.

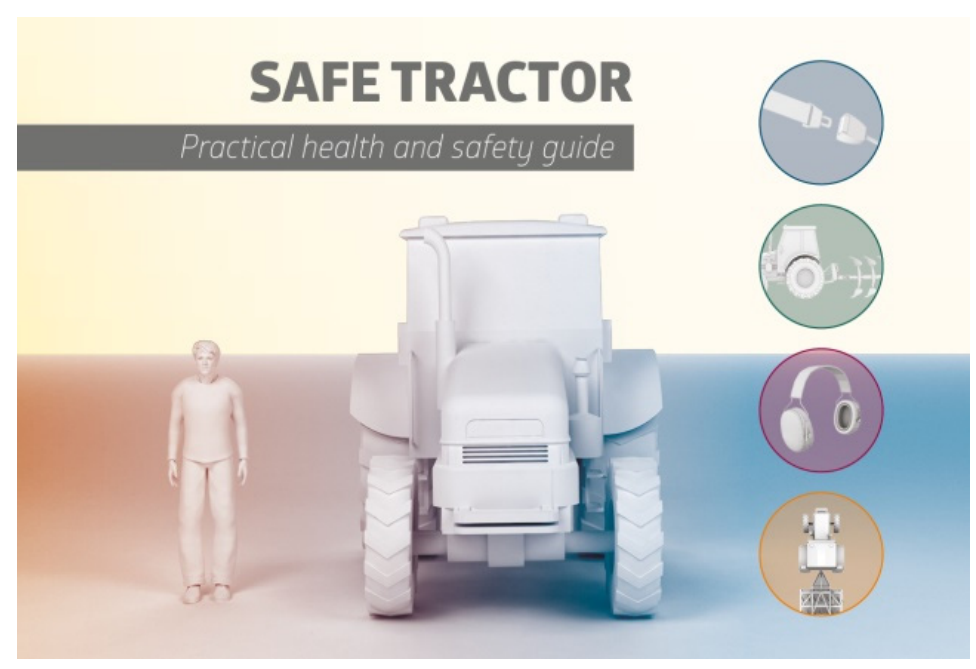

Figure 8. The cover with the four colours of the different sections included. 
At the very beginning of the manual, some information on the latest data on accidents is visualized in graphic form (Figure 9). This helps to convey the information, make it easy to memorize and read, and to share the dimension of the problem.

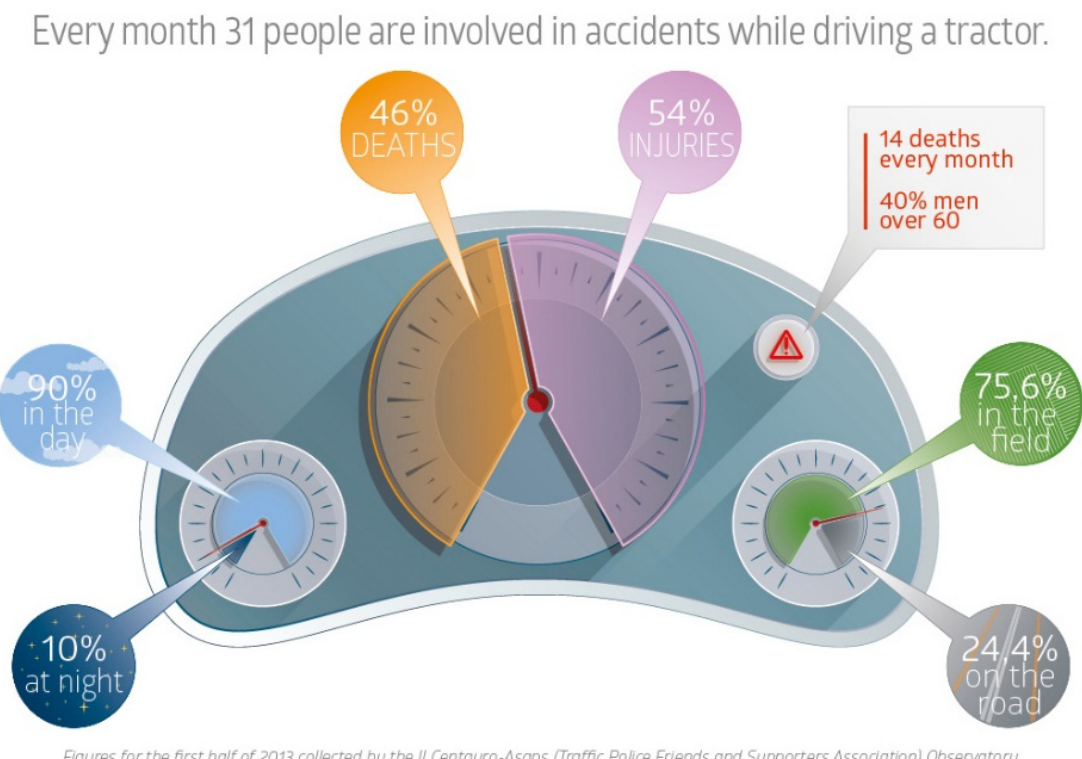

Figures for the first half of 2013 collected by the II Centauro-Asaps (Traffic Pollce Friends and Supporters Assodation) Observatory

Figure 9. Example of graphic information on the latest data on accidents.

Every topic in the manual includes a short sentence (Figure 10) or figure (Figures 11 and 12) that summarizes real cases on fatalities to attract attention and get users to actively read it.

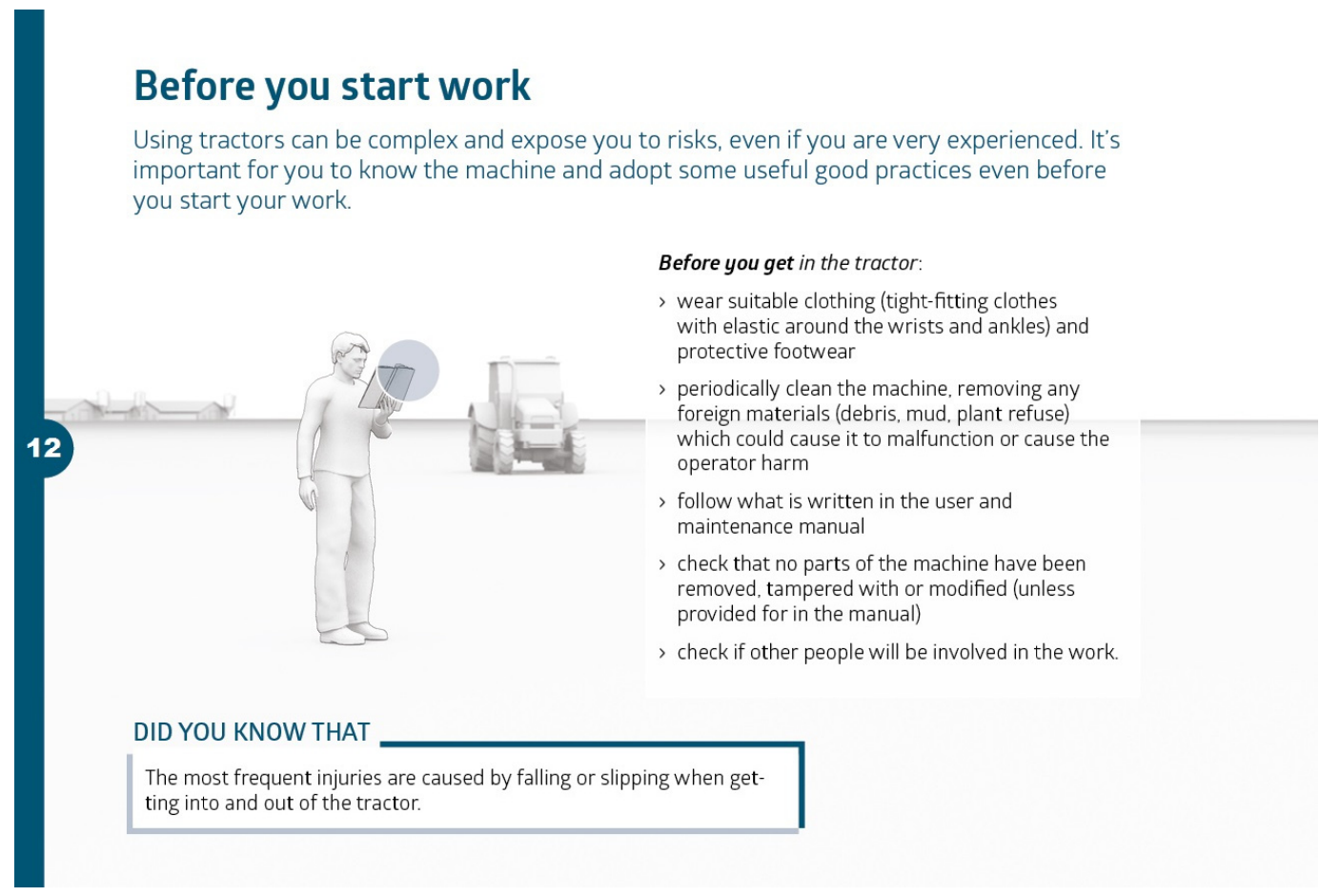

Figure 10. Example of a short sentence introducing every topic in the manual reports. 


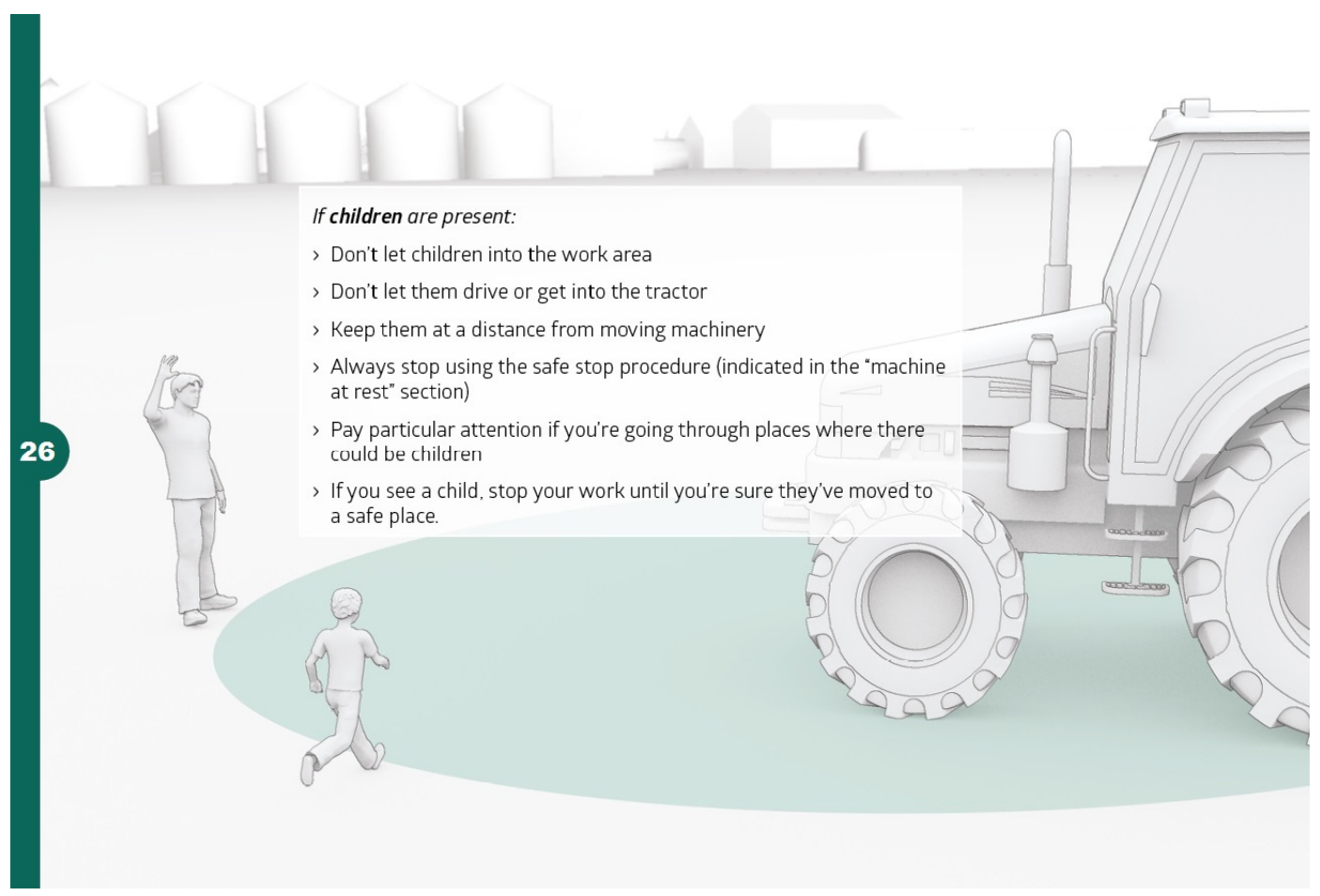

Figure 11. Example of a figure adopted to attract attention.

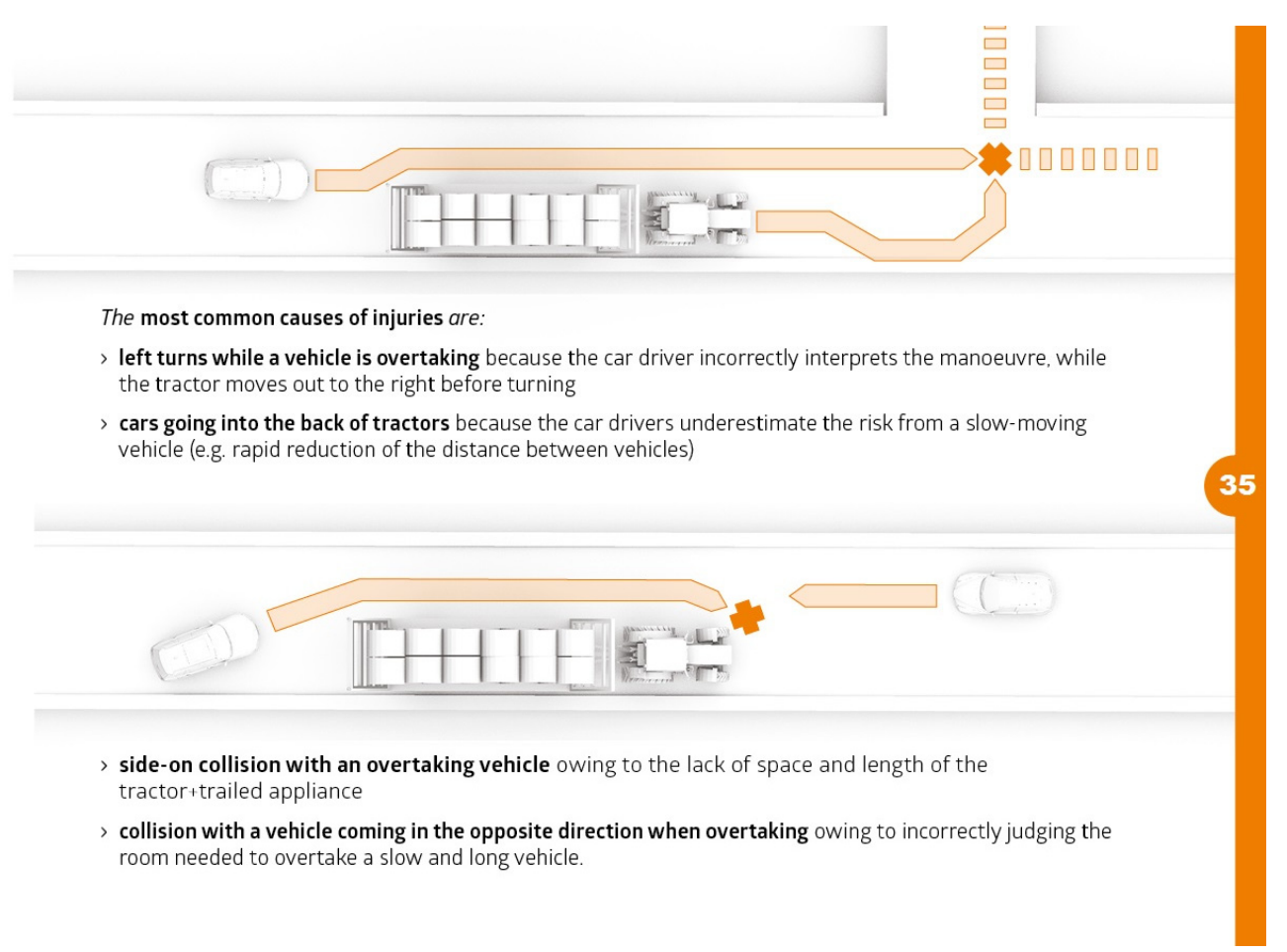

Figure 12. Example of a figure summarizing real cases of fatalities.

In order to only convey the information that the users consider useful for their particular work, every topic is set out over a maximum of two pages, which include short introductory texts and bullet points containing the main information to know or use to work in safety.

Some topics have boxes with further information. These have a dual function: 
- the boxes labelled "Did you know that" contain additional information on frequent procedures and/or situations (Figure 10);

- the boxes labelled "Be careful" (in red, the colour used to underline situations of possible danger) contain further bullet points with actions to do and precautions to bear in mind before performing procedures (Figure 7).

The texts alternate with explanatory and practical illustrations (Figure 13) to use as concrete visual examples of what is relayed in the manual. Some pages contain colour spots to underline the behaviour to apply in the described operations.

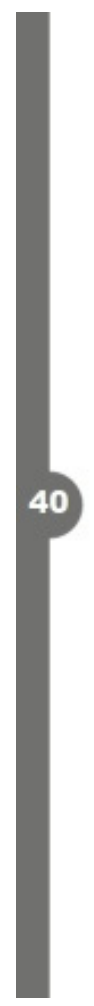

\section{Safety signs on tractors with mounted equipment}
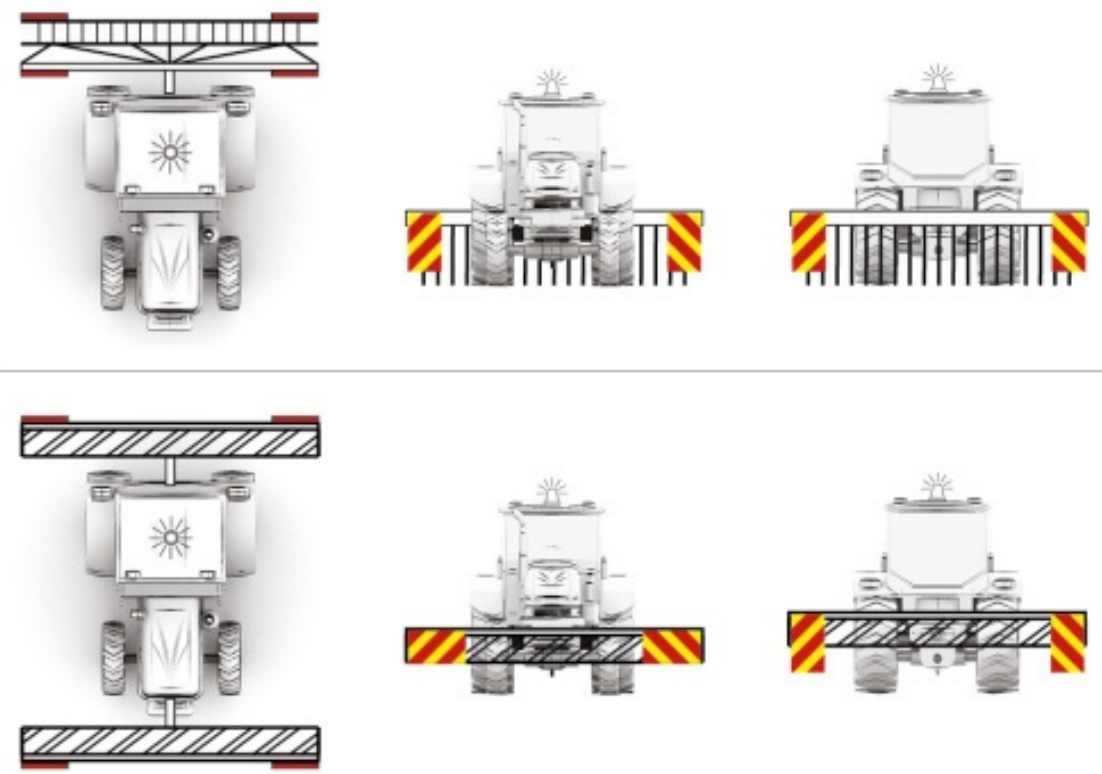

Figure 13. Example of practical illustrations.

\section{Discussion}

The "Safe Tractor" manual can be considered the first example of a publication in the farming sector created from its users' requirements. Through a participatory HCD approach, the users were involved in all the phases to create the manual.

A generational hierarchy was displayed in the interaction among the participants; the older users or those with more years of work experience were the ones who expressed their opinions with more conviction and more often, while the younger users intervened by confirming the opinions of their older colleagues or rejecting them, but only in part. The group leaders nevertheless played a positive role as they encouraged the others to participate actively in the discussion by responding promptly to the stimuli given by the moderator and proposing possibilities for change and improvement.

The final manual prototype has a new feature, that is, the print medium. Indeed, bearing in mind the conditions in which a tractor is normally used (high levels of damp, dust and at times dirt), which can damage the paper of a normal manual, and considering how the user consults it (in uncomfortable positions, in a hurry, sometimes wearing gloves), which can lead to whole or parts of pages being torn, it was decided to print the whole manual on a highly resistant artificial medium. The chosen material, which can be handled like ordinary paper, is biaxially oriented polypropylene film, or BOPP (Kartaplastic $^{\circledR}$, Tecnofoil srl, Azzano Decimo, Pordenone, Italy). This material is more resistant to 
ripping and more waterproof than paper but has a similar appearance and likewise can be printed on and recycled.

Right from the start of the research project, the users' support was deemed fundamental in selecting the topics to include in the publication and, more in general, in assessing their efficacy.

The result is a manual that includes information on what to know before getting into the driver's seat in "Vehicle at Rest". "Work in the Field" explains how to safely perform day-to-day activities; "On-road Transport" suggests how to avoid accidents with other vehicles' and "Occupational Illnesses" gives advice on how to prevent health problems.

The validation and assessment process envisaged by the HCD approach has not ended and may continue after the publication of the manual to iteratively improve it with every new edition. In this view, it is hoped that it will be possible to further the research by working on quantitative metrics as well by expanding the topics dealt with (e.g., first aid) and by involving other types of users (e.g., women, foreign workers). The authors should discuss the results and how they can be interpreted in light of previous studies and of the working hypotheses.

Acknowledgments: This study was funded by the INTRAC project, "Integration of ergonomic and safety aspects in agricultural tractors" funded by the Italian Ministry of Agricultural, Alimentary, and Forestry Policies, (MiPAAF; D.M. n. 12488/7303/11 of 09/06/2011).

Author Contributions: Carlo Bisaglia, Maurizio Cutini, and Simon Mastrangelo conceived and designed the experiments; Maurizio Cutini, Simon Mastrangelo and Giada Forte performed the experiments; Simon Mastrangelo, Giada Forte, Marco Maietta, and Maurizio Mazzenga analyzed the data; Marco Maietta and Maurizio Mazzenga followed the graphic design and Maurizio Cutini and Giada Forte wrote the paper.

Conflicts of Interest: The authors declare no conflict of interest. The founding sponsors had no role in the design of the study; in the collection, analyses, or interpretation of data; in the writing of the manuscript; or in the decision to publish the results.

\section{Appendix}

A list of the institutional publications analyzed by the authors to identify the editorial choices made to convey information on farm vehicle safety and maintenance to users.

- Adeguamento dei trattori agricoli o forestali (Technical adjustment of agricultural and forestry tractors)-INAIL, 2011.

- $\quad$ Agricoltura sicura (Safety agriculture), Azienda ULSS 20, Verona, 2010.

- Circolazione e sicurezza delle macchine agricole (traffic and safety of the agricultural machines), Egaf, 2003.

- Coltiviamo la cultura della sicurezza-La trattrice, (Let's cultivate the safety culture-The tractor) Veneto Agricoltura e INAIL, 2011.

- Come adeguare i trattori e le motoagricole usate (How to adjust technically used tractors and general purpose tractor), Regione Lombardia e INAIL, 2011.

- Compendio delle principali misure di sicurezza da applicare alle trattrici agricole (Summary of the main safety measures to apply to agricultural tractors), INAIL e Regione Lombardia, 2004.

- Ergonomics Checkpoints in Agriculture, International Labour Office in collaborazione con la International Ergonomics Association, 2012.

- $\quad$ Flyer trattrice, INAIL E ULSS Verona, 2009.

- Guida per l'adeguamento dei trattori agricoli e forestali (Guide for the technical adjustment of agricultural and forestry tractors)—Camera di Commercio Viterbo, 2008.

- I requisiti di sicurezza delle macchine irroratrici (Safety requirement of the sprayer machine)—ENAMA, 2002.

- L'installazione dei sistemi di ritenzione del conducente nei trattori agricoli o forestali (Installation of the driver's retention devices in agricultural or forestry tractors), Istituto Superiore per la Prevenzione e la Sicurezza del lavoro, 2009. 
- L'installazione dei dispositivi di protezione in caso di ribaltamento nei trattori agricoli o forestali (Installation of the rollover protective system in agricultural or forestry tractor, ISPESL, 2008.

- La sicurezza delle macchine agricole (Agricultural machines safety), ENAMA, 2002.

- La sicurezza delle macchine agricole e degli impianti agro-industriali (Safety in agricultural machine and agro-industrial facilities), Associazione italiana di Ingegneria Agraria e ISPESL, 2002.

- Manuale della circolazione delle macchine agricole (Agricultural machines traffic manual), Regione Veneto e Polizia locale, 2009.

- Macchine semoventi ‘Trattrici agricole a ruota' Sicurezza, (Self-propelled machines 'Agricultural wheeled tractor', Safety) CNR Torino, 2011.

- Manuale delle procedure di sicurezza (Safety procedure manual), Servizio sanitario regionale Emilia Romagna, 2011.

- Manuale per un lavoro sicuro in agricoltura (Manual for a safe work in agriculture), Regione Veneto, 2006.

- Sintesi delle norme di circolazione stradale riguardanti le macchine agricole (Summary of the rules of the road for agricultural machines), ENAMA, 2011.

\section{References}

1. European Commission (EC). The Magnitude and Spectrum of Farm Injuries in the European Union Countries; EC: Athens, Greece, 2004.

2. Health and Safety Authority (HSA). Farm Safety Action Plan 2013-2015; Health and Safety Authority (HSA): Dublin, Ireland, 2013.

3. Osservatorio INAIL Sugli Infortuni Nel Settore Agricolo e Forestale. In Report Annuale Sugli Infortuni Mortali e Con Feriti Gravi Verificatisi Nel 2014 Nel Settore Agricolo e Forestale; Dipartimento Innovazioni Tecnologiche e sicurezza degli Impianti, Prodotti e Insediamenti Antropici: Rome, Italy, 2015.

4. Pyykkonen, M.; Aherin, B. Occupational Health and Safety in Agriculture. In Sustainable Agriculture; Jakobsson, C., Ed.; Baltic University Press: Uppsala, Sweden, 2012; pp. 391-401.

5. ASAPS. Asaps Associazione Sostenitori Amici Della Polizia Stradale, Report Primo Semestre 2013 su Incidenti ai Trattori Agricoli, Osservatorio Morti Verdi il Centauro; ASAPS: Forlì, Italy, 2014.

6. EC. Directive 2003/59/EC of the European Parliament and of the Council of 15 July 2003 on the Initial Qualification and Periodic Training of Drivers of Certain Road Vehicles for the Carriage of Goods or Passengers; EUR-Lex: European Parliament, 2003; Available online: http://eur-lex.europa.eu/legal-content/EN/ALL/?uri= CELEX\%3A32003L0059 (accessed on 3 August 2017).

7. ISO. ISO 26800:2011: Ergonomics—General Approach, Principles and Concepts; International Organization for Standardization: Geneva, Switzerland, 2011.

8. ISO. ISO 13407: 1999 Human-Centred Design Processes for Interactive Systems; International Organization for Standardization: Geneva, Switzerland, 1999.

9. ISO. ISO 9241-210: 2010 Ergonomics of Human-System Interaction-Part 210: Human-Centred Design for Interactive Systems; International Organization for Standardization: Geneva, Switzerland, 2010.

10. Abras, C.; Maloney-Krichmar, D.; Preece, J. User-Centred Design. In Bainbridge 2004, W. Encyclopedia of Human-Computer Interaction; Sage Publications: Thousand Oaks, CA, USA, 2004.

11. Norman, D.A.; Draper, S.W. User-Centred System Design: New Perspectives on Human-Computer Interaction; L. Erlbaum Associates Inc.: Hillsdale, NJ, USA, 1986.

12. Norman, D. The Design of Everyday Things; Doubleday: New York, NY, USA, 1988.

13. Sanders, E.B.N. From User-Centred to Participatory Design Approaches. In Design and the Social Sciences 2002; Frascara, J., Ed.; Taylor \& Francis: Oxford, UK, 2002.

14. Preece, J.; Rogers, Y.; Sharp, H. Interaction Design: Beyond Human-Computer Interaction; John Wiley \& Sons, Inc.: New York, NY, USA, 2002.

15. Vredenburg, K.; Mao, J.; Smith, P.; Carey, T. A Survey of User-Centred Design Practice. In Proceedings of the SIGCHI Conference on Human Factors in Computing Systems, Minneapolis, MN, USA, 20-25 April 2002.

16. Maguire, M. Context of use within usability activities. Int. J. Hum. Comput. Stud. 2001, 55, 453-483. [CrossRef] 
17. UNI. Technical Documentation of Product-Instructions for Use-Articulation and Exposition of The Content; Ente Italiano di Normazione: Milan, Italy, 2000.

18. Langford, J.; McDonagh, D. Focus Groups Supporting Effective Product Development; Taylor \& Francis: Oxford, UK, 2005.

19. Caplan, S. Using focus group methodology for ergonomic design. Ergonomics 1990, 33, 527-533. [CrossRef]

20. Fincher, S.; Tenenberg, J. Making sense of card sorting data. Expert Syst. 2005, 22, 89-93. [CrossRef]

21. Mastrangelo, S.; Verna, U.; Spirito, L. Applicazione della metodologia User-Centred Design (UCD) a Prodotti Editoriali per Una Manualistica Usabile, Atti del IX Congresso Nazionale Società Italiana di Ergonomia; SIE, Società Italiana di ergonomia: Rome, Italy, 2010.

22. Krueger, R.A. Focus Groups: A Practical Guide for Applied Research; Sage: Thousand Oaks, CA, USA, 1994.

23. Nielsen, J. Card Sorting: How Many Users to Test. Available online: https:/ /www.nngroup.com/articles / card-sorting-how-many-users-to-test (accessed on 4 August 2017).

24. European Commission (EC). How to Write Clearly; European Commission: Luxembourg, Luxembourg, 2012.

25. Kirwan, B.; Ainsworth, L.K. A Guide to Task Analysis: The Task Analysis Working Group; Taylor and Francis: Oxford, UK, 2005.

26. Stanton, N.A. Hierarchical task analysis: Developments, applications and extensions. Appl. Ergon. 2006, 37, 55-79. [CrossRef] [PubMed]

27. Adams, J. Risk; UCL Press: London, UK, 1995.

28. Keene, E.O.; Zimmermann, S. Mosaic of Thought: Teaching Comprehension in A Reader's Workshop; Heinemann: Portsmouth, NH, USA, 1997.

(C) 2017 by the authors. Licensee MDPI, Basel, Switzerland. This article is an open access article distributed under the terms and conditions of the Creative Commons Attribution (CC BY) license (http:/ / creativecommons.org/licenses/by/4.0/). 